INTERNATIONAL JOURNAL OF MULTidisciplinARY RESEARCH AND ANALySis

ISSN(print): 2643-9840, ISSN(online): 2643-9875

Volume 04 Issue 03 March 2021

DOI: $10.47191 /$ ijmra/v4-i3-13, Impact Factor: 6.072

Page No.- 304-315

\title{
Business Intelligence Applications; sustaining Retail Businesses in Rivers State, Nigeria
}

\author{
Patrick N Nwinyokpugi ${ }^{1}$, Fiito Dumnamene Lah ${ }^{2}$ \\ ${ }^{1,2}$ Department of Office and Information Management Rivers State University, Nigeria
}

ABSTRACT: The contemporary retail outlets are no more run by manual practices given the electronic nature of company to customers (C-C); customers to customers (C-C) transactions globally. The application of business intelligence has given an edge to retail outlets operation. This study therefore, strives to examine the relationship between business intelligence application and retail business sustainability in Rivers State, Nigeria. The study used descriptive research technique through the adoption of crosssectional survey design. Nine judgmentally sampled retail outlets especially large scale malls \& superstores were studied in Port Harcourt base on their inherent electronic driven operations. Using structured closed ended questionnaire, 45 census senior managers of these sampled retail outlets were studied. Data gathered were analysed using the Pearson Product Moment Correlation Coefficient (PPMCC) statistics and presented with the aid of SPSS version 20.0 for easy interpretation. The results of analysed data showed that, the dimensions of business intelligence application which included but not limited to customers' performance management, data warehouse, data mining and advanced data visualization significantly correlated positively with the measures of retail business sustainability being profitability and customers' patronage. The finding also showed a high moderating effect of organizational culture on business intelligence application and retail business sustainability in Rivers State, Nigeria. Relying on the empirical findings, the study concluded that business intelligence application has positive significant relationship with retail business sustainability. It is therefore recommended that, the dimensions of business intelligence: customers' performance management, data warehouse, data mining \& advance data visualization identified in this study should be utilized as it enhances retail business operational sustainability.

KEYWORDS: Business Intelligence, Performance Management, Data Warehouse, Data mining and Advanced data Visualization

\section{INTRODUCTION}

In the present context of increasing globalization, rapid technological advancement, and the move towards a knowledge base economy, companies need to become technologically empowered to act in competitive environment, (Sousa, 2020). For decades now, oil companies rule the world. An immense, untapped valuable asset of the 18th century, oil was the world's most valuable resource. It was the key functionality of everything from the government to local companies' operations. Without it, progress would halt and economies would shrink. Today, the perceptions for the $21^{\text {st }}$ century business operation have change. A new particular wonder that amazes the world, the advent of robots makes the difference between these two centuries look like the two different ends of a wide spectrum. And this is even more amazing because, present day technology, phone, radio, internet, brings the world to you. But if the trends continue, robots will soon bring you to the world, and at the speed of light. These changes here occur due to the power of the most useful resource of the 21st century. Data is an essential resource that powers the information economy in much the way that oil has fuelled the industrial economy. The advent of information technology (IT) has help organizations increase digitalization of their products. Data computing provide a scalable and cost effective platform for organizations to capture, store, analyse, and consume large amounts of data. To this end, managers of retail business organization shifted focus to business intelligence applications as a solution to sustain business growth. The term business intelligence first appeared in 1989 and was pioneered by Howard Dresner of Gartner research, a consulting firm in the United States. Other scholars have attempted to provide understanding about this novel tools at various industrial levels. Turban, et al (2010), see business intelligence as an umbrella term that encompasses tools, architectures, databases, data warehouses, performance management, methodologies, and so forth, all of which are integrated into a unified software suite. Thinking along this line, Wixom \& Watson(2010), stated that, we are living now through the early decades of the information revolution, and it's a miracle of human 


\section{Business Intelligence Applications; sustaining Retail Businesses in Rivers State, Nigeria}

energy and ingenuity. Never before has so much information been available, so easily and inexpensively, about so many subjects, especially business organization. The most important thing is that information is like water. It's vital to our lives; we cannot survive without it. But if too much pours over us, we drown. To keep from drowning in information we must learn to use it properly, which means figuring out what the information is telling us. After all, it isn't the information itself we use to make decisions; it's the knowledge within the information that we use. This is why we must learn how to analyze information; how to determine what information we need to make the decisions we face, how to get that information, and then the most crucial step of all is how to reach inside this information to grasp the knowledge it contains. McKay (2010).

The Nigeria's retail sector remains relatively under developed. More than $80 \%$ of the shopping is still carried out at the traditional shops such as corner shops, kiosks, local markets and also from street vendors. Nevertheless, the sector is seeing a shift towards modernisation as the economy grows and diversifies. The trend towards modernisation will continue as the rate at which the population is shifting from rural to urban areas continues. Olajide(2018) drawing a position from the McKinsey report, submitted that Nigeria's rate of urbanisation is one of the fastest in the world, with ongoing urbanisation rate estimated at 4 per cent per annum. Retailers today can no longer be accurately characterized as merchant intermediaries that buy from suppliers and sell to customers. Rather, they are best described as conductors of two sided platforms that serve as ecosystems in which value is created and delivered to customers and, subsequently, appropriated by the retailer and its business partners. Viewing retailing as spaces (sometimes, virtual) for staging customer experiences require business models that go beyond traditional functions of procuring, stocking, and moving products.

\section{LITERATURE REVIEW}

As the challenges of business organization in the turbulent environment become enormous, the strategy that business managers can develop to end this challenge in order to sustain business activities depends on current trend of information technology. Business intelligence application, a tool that give business actors the opportunities to collect data, organize, analyse and present business information with the aim of taken decision that enhances organizational sustainability. Business is a game between two or more actors involving buying and selling with the aim of making profits, while the customers are expected to buy quality products and services that worth the value for their money at the right time and at the right place. As the competition in the business world increases, customers are constantly searching for business outlets that can provide needed essentials for them at an affordable price. This becomes necessary because visited outlets that cannot provide the needed essentials will create pathway for the customers to check other business outlets that can meet up with their demand. Business intelligence is a framework that transforms information into data and afterward into learning, consequently enhancing company's basic decision-making process. helps administrators by breaking down information from various resources in better basic leadership level both at tactical and strategic level, for customary utilization, conventional data frameworks farewell, yet for hierarchical and functional planning; new tools are required for business analysis, (Rasoul and Mohammad, 2016). The working definition of business intelligence applications as adopted in the study sees Business Intelligence as all those tools that enable business organization to collect data, integrate, analyse and present business information with the objectives of making decision that enhances business sustainability. One simplest thing that business intelligence applications do for business organization is that, its enable managers to gather data related to the business performance. In most of the literature review definition found on business intelligence context, we always see the word data, information, and knowledge which could confuse our understanding on its use and implications.

Customer service involves not just order entry, but various activities that are distributed throughout the average organization in various departments: credit, distribution, forecasting, sales, shipping, planning, scheduling, traffic, accounts receivable, and manufacturing. These activities are usually the responsibilities of different functional units, which treat and manage their components of customer service independently and differently from all other units. Addressing customer-service process using the traditional, situational techniques might result in improvement to one or more activities of a specific procedure or department, but not to the process of customer service as a whole. Additionally, not addressing other functions outside customer service which may very well be related to customer service in ways that are not immediately apparent - might mean that benefits gained either will not be sustained or will be negated. Consequently, the customer may never see the results of the effort. Reengineering through reinventing, on the other hand, recognizes that the process of customer service spans many parts and levels of the typical organization, and it addresses all of those parts and levels. It arranges all activities associated with customer service previously divided into separate units into processes that have a continual flow, accelerated velocity, a consolidated function, and a common system of management practices and performance measurements. This organizational restructuring leads to uniformity in ways of dealing with customers and greatly increases the probability that customers will see the results of the change efforts.

Data Warehouse: A warehouse is a database that is optimized for decision support"; that explains the extensive acquisitions of these centralized data-driven repositories as basis to serve the need for highly integrated enterprise-wide information (Tiwari, 


\section{Business Intelligence Applications; sustaining Retail Businesses in Rivers State, Nigeria}

2007). However, organizations are eager to cut down the negative impacts of this huge information technology investments, and therefore keen to measure the illusive factors behind successful information systems. However, the means to retrieve and analyze data, to extract, transform and load data, and to manage the data dictionary are also considered essential components of a data warehousing system. Many references to data warehousing use this broader context. Thus, an expanded definition for data warehousing includes business intelligence tools. In essence, the data warehousing concept was intended to provide an architectural model for the flow of data from operational systems to decision making environments. Data warehouses are computer based information systems that are home for "secondhand" data that originated from either another application or from an external system or source. Data warehouses are read-only, integrated databases designed to answer comparative and "what if" questions. An active warehouse is boosted online and so achieves a beneficial reliability between the stored information and the data modernizations. Data warehouses regulate the data across the association to contain a single view of information. Extraction-transformation-loading (ETL) tools are the part of software responsible for the removal of data from various sources, its refining, customization, reformatting, combination, and insertion into a data warehouse. Constructing the extraction transformation loading (ETL) process is the biggest tasks of constructing a warehouse. It is difficult, time consuming, and uses many data warehouse project's realization efforts, costs, and resources. Constructing a data warehouse needs focusing directly on recognizing three main areas: the source area, the destination area, and the mapping area (ETL processes). The efforts are performed to conceptualize the ETL processes. Data warehouse contains historical information that is collected from various heterogeneous data sources that extended in all areas of globe for the function of decision making supports. The queries for decision making are systematic, difficult in nature and the response time is high after functioning of large data warehouse. Materialized view selection is the important technique to plan the data warehouse in possible manner that reduced query response time by materializing views over a data warehouse. Materialized view selection helps efficient query processing, the information in the data warehouses is usually stored as a set of materialized views which reduce the view preservation and query processing costs. Reyan and Ahmed, (2014), stated that, data warehouse is a combined set of data obtained mainly from operational data to utilize decision making strategy and business intelligence using (OLAP) techniques. The aim therefore is to increase the considered information delivery system for strategic decision making to business executives for sketching the business approaches, generated goals, setting ideas and observing end results. Data warehouse is necessary to offer suitable information to business executives. Consequently, many fresh data in data warehouse are available to formulate new consistent decisions by the managers and executives.

Data Mining: The term data mining was coined in the 1960s. Data collection abilities were starting in the 1960s. Data mining was used to find basic information from the collections such as total revenue over the last three years. The technologies that made this possible consisted of tapes, disks, and computers. Interestingly, we are in an age often referred to as the information age. In this information age, because we believe that information leads to power and success, and thanks to sophisticated technologies such as computers, satellites, etc., that have emerged and we have been collecting tremendous amounts of information. Initially, with the advent of computers and means for mass digital storage, we started collecting and storing all sorts of data, counting on the power of computers to help sort through this mixture of information. Unfortunately, these massive collections of data stored on disparate structures very rapidly became overwhelming. This initial chaos has led to the creation of structured databases and database management systems (DBMS). One of the latest applications of data mining can be found in Torabi et al (2018), where they developed a new prediction model for energy production with wind turbines. However, in this study data mining is defined as the process that involved the extraction of valuable information from a large data sets store in the organization data warehouse. The efficient database management systems have been very important assets for management of a large quantity of data and especially for effective and efficient retrieval of particular information from a large collection whenever needed. The proliferation of database management systems has also contributed to recent massive gathering of all sorts of information. Today, we have far more information than we can handle: from business transactions and scientific data, to satellite pictures, text reports and military intelligence. In today's world, there are many ways to apply data mining concepts and techniques. The most known way of applying these data mining techniques is in the field of business. Businesses have many uses of data mining. It can be used internally in the business, for example, to predict employee actions and used externally to identify possible customers and to help efficiently market its products. Data mining is not limited to just business. It is being developed to work in the field of health care as well as many different fields. Data mining gets its name from the similarities between searching for valuable information in large data sets and mining a mountain for valuable elements. Data mining, in the simplest sense, is knowledge discovery (Bengio, Buhmann, Embrechts, \& Zurada, 2012). It consists of the searching, analyzing and sifting through large data sets to find new patterns, trends, and relationships contained within. There are three general properties that the discovered knowledge should satisfy in the data mining process. First, it should be accurate, second, it should be comprehensible, and thirdly, it should be interesting. The data mining process of organization information discovery involves seven phases from the beginning to the end; 


\section{Business Intelligence Applications; sustaining Retail Businesses in Rivers State, Nigeria}

phase one, data integration - which involves the source of data collection, phase two, data selection - involve the process of selecting useful data, phase three - data cleaning: rids data of errors, missing values, and inconsistent data, phase four data transformation - normalization, smoothing, other form data mining technique, phase five - data mining - applying data mining techniques to discover patterns of extracting relevant data, phase six-pattern evaluation/ presentation; involving visualization and removing of redundant patterns and phase seven which is the last phase is knowledge discovery - use to make decisions.

Advanced Data Visualization: Advanced data visualization involves presenting data in graphical or pictorial form which makes the information easy to understand. It helps to explain facts and determine courses of action. It benefits cut across any field of study that requires innovative ways of presenting large, complex information. The advent of computer graphics has shaped advance visualization. There has been the need for displaying massive amounts of data in a way that is easily accessible and understandable. (Sancho, 2014). Data visualization is the visual and interactive exploration and graphic representation of data of any size, type (structured and unstructured) or origin. Organizations generate data every day; as a result, the amount of data available on the web has increased dramatically. It is difficult for users to visualize, explore, and use this enormous data. The ability to visualize data is crucial to scientific research. This enables decision makers to see analytics in visual form and makes it easy for them to make sense of the data. It helps them discover patterns, comprehend information, and form an opinion. Advanced data visualization is also regarded as information visualization or scientific visualization. Things that can be visualized include visible reality that people can see (person, world, nature), hidden reality that normally be hidden (earth core, blood, universe), invisible reality (wind, air, heat, electron, sound, smell), and abstract things (data, idea, hierarchy, process, relationship). The purposes of visualizing data are multifold, ranging from general comprehension and understanding of ideas, supporting information behaviours (analysis and decision support, information seeking, browsing, navigation), to artistic (beauty) expression and appreciation (Viégas and Wattenberg, 2007). In contrast, the goals of visualizing business data are focused on human information seeking and decision-making behaviours, particularly in two broad goals: (i) visualizing key metrics for easy and fast comprehension which directly facilitates decision-making; (ii) providing a visual and interactive way to explore data. Such visualizations often use simple, standard, and abstract charts or diagrams, and utilize data binding techniques at the backend. Both research and practices have shown data visualization's value and contribution to the decision process. More specifically, visualization eases the cognitive load of information processing, and it helps one recall or memorize data easily because of the perceivable image, Borkin et al., (2013). Basically, business intelligence results are presented in the form of reports, dashboards, and analytical tools. Among these, dashboards are mostly data visualization driven. Reports are traditionally static and noninteractive, and they present the information to the user in form visual graphics. Embedded visuals are visual effects embedded in another form of presentation. They are not independently presented but always used on top of other presentation forms. Embedded visuals include two major forms: conditional formatting and inline mini charts (or Sparkline). Conditional formatting refers to the direct formatting or styling of text, numbers, shapes, and other contents utilizing visual variables like colour, size, etc. (Bertin, 2010). Conditional formatting does not significantly change the layout and flow of contents, thus it is less intrusive to the content. Instead, it provides a decorative effect that reveals more meaning or high lights selected content from the data or text. Basic types of charts include line charts, bar charts, pie charts, etc., and examples of diagrams include organization structure diagrams, tree diagrams, network diagrams, workflows diagrams, etc. Other more specific types of charts are used in different business contexts for more specific purposes. These charts are based on the more generic chart types like bar charts and line charts, and add more specific visual elements, or arrange the elements in a specific way to represent domain-specific meanings. For instance, bullet charts (based on bar charts) are used in performance measuring; perceptual maps (based on scatter plots) are used in marketing; waterfall or bridge charts (based on column charts) are used in driving factor analysis; Gantt charts (based on data tables and bar charts) are used in project management; funnel charts are used in sales; candlestick charts are used in stock technical analysis.

Locations play an important role in many areas of business data analysis and decision-making. Many business activities are associated with locations. It has been gaining increased attention especially with the wide adoption of location sensors (like GPS and other location capture technologies) which generate location data. Location based visuals, commonly based on a map, provide a background or a context that is familiar to the users and make the location related data more comprehensible and perceivable. (Dresner, 2015). The term dashboard originally came from operational status monitoring on machines which provides visual display for quick reading. Its use has been expanded to visualization of digital data associated with business performance on screens (Few, 2004). A dashboard (at the frontend) is basically an integrated application of data (content), visual views, and user interface/interaction (UI). Dashboard = Data + Visualization + User Interface. The data on the dashboards primarily consists of metrics, key performance indicators (KPIs), and textual information. Metrics (or measures, indicators) are numerical values that measure various aspects of the business activities. Personal or self-service BI: Self-service business intelligence features control in the hands of users, especially power users. This group of people is highly skilled in using technology applications in business 


\section{Business Intelligence Applications; sustaining Retail Businesses in Rivers State, Nigeria}

tasks, and they often need instant results. They are able to use computer tools and languages to get what they want with little assistance from their information technology (IT) departments. Some of the tools like Tableau and Power BI have quickly risen to satisfy this need using a visualization-driven approach and gained wide recognition, (Sallam, 2017). Retailing is a socio-economic system, which brings people together, to exchange goods and services for a small consideration; which matches the needs of people, the ultimate consumers, with those of manufacturers and agriculturists, which not only satisfies the essential daily necessities of life but also promotes new lifestyles, thus peace, happiness and prosperity in the community (Rudrabasavaraj, 2010). The word retail originated from a French word "retailer", that means to cut a piece off "or" to break bulk". In other words, it shows a first hand-transaction with the customer (Sharma, 2008; Dhotre, 2010). Amit \& Kameshvari, (2012) define retailing as a group of activities where goods and services are marketed to final consumers for personal or household consuming. Retailing does this by making them available on a massive extent and offering them to consumers on a relatively small extent. Since consumers have become more mobile and their behaviour has changed. Retailing business has emerged to this challenge and transformed markets at home and abroad (Fernie et al., 2012). Lubin and Esty (2010), too, believe that the orientation toward business sustainability will join the list of megatrends, such as business globalization and large-scale implementation of the advancements in information technology, which will impose new strategic mandates on business leaders. However, Cândea (2010) points out that there is no consensus with respect to the favourable effect of a good social and environmental behaviour.

\section{METHODS}

As a descriptive research that adopted the cross sectional survey design, this study covered 16 retail outlets in Port Harcourt as the study population frame. A pilot study was conducted on the 16 retail outlets to enable the selection of ideal retail outlets that have business intelligence index in their respective operations. Result of our pilot study enable us to record nine (9) retail outlets in Port Harcourt out of the 16 retail outlets that met the study criteria. These include: Spar, Market Square, Next Cash \& Carry, Everyday Emporium, Next time Supermarket, Nengi Bio Supermarket, Prudent Supermarket, Turning Point Supermarket and Liverpool Supermarket. This study falls under the purview of the intelligence unit of the business which is not open to the entire employees of the organizations, therefore, a macro level study allows us to focus only on managerial employees of the nine (9) retail outlets for our study population. Category of managerial cadre are: General Manager, warehouse manager, Logistics manager, Supervisor sales and supervisor customer's service. Therefore, five managerial employees of the above cadre form the study population. However, because of the finite nature of the study population, the entire respondents' elements are studied. This research study covers the entire forty-five (45) targeted populations. Therefore, a census was adopted for sampling target respondents. The questionnaire was carefully design using structured closed-ended questionnaire method in the four points Likert scale with VHE as Very High Extent (4); HE is High Extent (3), ME as Moderate Extent, (2), and LE as Low Extent (1)

Table 1: Number of retail outlets for the target population

\begin{tabular}{|l|l|l|c|}
\hline SN & Names of Retail Outlets & Mgrs /per outlets & Sample size \\
\hline 1. & Spar & 5 & 5 \\
\hline 2. & Market Square & 5 & 5 \\
\hline 3. & Next Cash \& Carry & 5 & 5 \\
\hline 4. & Everyday Emporium & 5 & 5 \\
\hline 5. & Next time Supermarket & 5 & 5 \\
\hline 6. & Nengi Bio Supermarket & 5 & 5 \\
\hline 7. & Prudent Supermarket & 5 & 5 \\
\hline 8. & Turning Point Supermarket & 5 & 5 \\
\hline 9 & Liverpool Supermarket & 5 & 5 \\
\hline & Total & 45 & 45 \\
\hline
\end{tabular}

Source: Researchers Desk, 2020

The reliability of the structured questionnaire was ascertained through Test-re-test in which a pilot administration of the study instrument (questionnaire) was made on a portion of the chosen sample and administered to the respondents and retrieved after two months. Analysis of collected data determined by correlation coefficient and presented with the Statistical Package for Social Sciences version 20. The reliability of the study variables is anchored on the Cronbach Alpha, as only variables with the return above $\mathbf{0 . 7 2}$, was considered reliable in the study. Below is the presentation of the respective reliability values. 
Business Intelligence Applications; sustaining Retail Businesses in Rivers State, Nigeria

Table 2: Cronbach Alpha Reliability Coefficients of the variable measures

\begin{tabular}{lllll}
\hline S/N & $\begin{array}{l}\text { Dimensions/Measures/moderating } \\
\text { Variable }\end{array}$ & $\begin{array}{l}\text { Numbers } \\
\text { items }\end{array}$ & $\begin{array}{l}\text { Numbers } \\
\text { of Case }\end{array}$ & $\begin{array}{l}\text { Cronbach } \\
\text { Alpha ( } \boldsymbol{\alpha})\end{array}$ \\
\hline 1. & Customers' Performance Management (CPM) & 4 & 40 & .996 \\
2. & Data warehouse (DW) & 4 & 40 & .996 \\
3. & Data Mining (DM) & 3 & 40 & .997 \\
4. & Advanced data visualization (ADV) & 4 & 40 & .997 \\
5. & Profitability (P) & 4 & 40 & .995 \\
6. & Customers' patronage (CP) & 4 & 40 & .996 \\
7. & Organizational culture (OC) & 4 & 40 & .992 \\
\hline
\end{tabular}

Source: SPSS Result (Version 20)

\section{Methods of Data Analysis}

The Pearson's Product Moment Correlation Coefficient will be used to analyse the data. However, the analyses were categorized under three headings: primary analysis, secondary analysis and tertiary analysis. The primary analysis here involved the use of descriptive statistics. The secondary analysis here is the results for the test of the hypotheses stated earlier in chapter one. The analysis on the relationship between the variables will be carried out at $95 \%$ confidence interval and at 0.5 level of significance. The tertiary level of analysis involved the interpretation of the results of the secondary analysis which constitutes the findings with a view of making conclusions and recommendations. Below is the Pearson's Product Moment Correlation Coefficient formula.

Scatter graph is one of the techniques used in deciding whether a bivariate relationship does exist between interval scaled variables. In a bid to determine the existence and trend of this relationship, we plotted a scatter diagram as presented in the figure below business intelligence application as a predictor variable is plotted on the $X$ axis whereas retail business sustainability as the criterion variable is on the $Y$ axis.

$$
r=\frac{n \sum x y-\sum x \sum y}{\sqrt{\left(n \sum x^{2}-\sum x^{2}\right)\left(n \sum y^{2}-\left(\sum y\right)^{2}\right)}}
$$

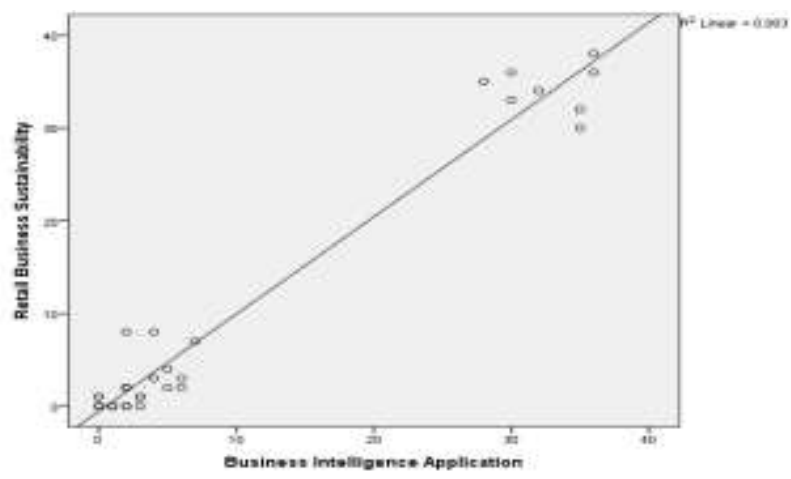

Figure 1: .Scatter plot showing influence of Business intelligence application on retail business sustainability

The figure 1 above shows a strong relationship between business intelligence application (independent variable) and retail business sustainability (dependent variable). The scatter plot graph shows at $R^{2}$ linear value of (0.963) depicting a strong viable and positive relationship between the two constructs. The implication is that an increase in business intelligence application simultaneously brings about an increase in the level of retail business sustainability.

Presentation of Results on the Test of Hypotheses

We had proposed nine research hypotheses in chapter one of this studied to seek explanation to the relationship between business intelligence application and retail business sustainability as well as the moderating influence of organizational culture in such relationship. The Pearson Moment Correlation Coefficient statistics was calculated using the SPSS version 20 to establish the relationship among the empirical referents of the predictor variable and the measures of the criterion variable. Correlation coefficients can range from -1.00 to +1.00 . The value of -1.00 represents a perfect negative correlation while +1.00 represents a perfect positive correlation. A value 0.00 represents a lack of correlation. In testing hypothesis $1-9$, the following rules were upheld in accepting or rejecting the null hypotheses. All the coefficient values that indicate levels of significance $(*$ or $* *)$ as calculated using SPSS were accepted and therefore, our null hypotheses rejected; when no significance is indicated in the 


\section{Business Intelligence Applications; sustaining Retail Businesses in Rivers State, Nigeria}

coefficient ( $r$ ) value, we accept our null hypotheses. Our confidence interval was set at the 0.05 (two tailed) level of significance to test the statistical significance of the data in this study.

Table 3: Correlation Matrix for customers' performance management and retail business sustainability

\begin{tabular}{|c|c|c|c|c|}
\hline & & $\begin{array}{l}\text { Customers' } \\
\text { Performance } \\
\text { Management }\end{array}$ & Profitability & $\begin{array}{l}\text { Customers' } \\
\text { Patronage }\end{array}$ \\
\hline Customers' & Pearson Correlation & 1 & $.992^{* *}$ & $.995^{* *}$ \\
\hline Performance & Sig. ( 2 tailed) & & .000 & .000 \\
\hline Management & $N$ & 40 & 40 & 40 \\
\hline \multirow{3}{*}{ Profitability } & Pearson Correlation & $.992^{* *}$ & 1 & $.989^{* *}$ \\
\hline & Sig. (2-tailed) & .000 & & .000 \\
\hline & $N$ & 40 & 40 & 40 \\
\hline \multirow{3}{*}{$\begin{array}{l}\text { Customers' } \\
\text { Profitability }\end{array}$} & Pearson Correlation & $.995^{* *}$ & $.989^{* *}$ & 1 \\
\hline & Sig. (2-tailed) & .000 & .000 & \\
\hline & $\mathrm{N}$ & 40 & 40 & 40 \\
\hline
\end{tabular}

**. Correlation is significant at the 0.01 level (2-tailed).

Source: Filed Data, 2020

The table 3 shows the correlation of hypotheses one and two; the hypothesis one showed a significant correlation at $r=.992^{* *}$ where $\mathrm{P}$-value $=.000(\mathrm{P}<0.001)$. This implies a strong and significant relationship between both variables at $95 \%$ level of confidence. We therefore rejected the null hypothesis (Ho:1), and upheld the alternate and restated, thus, there is a significance relationship between customers' performance management and retail business profitability in Port Harcourt, Rivers State, Nigeria. The hypothesis two show a significant correlation at $r=.955^{* *}$ where $P$-value $=.000(P<0.001)$. This implies a strong and significant relationship between both variables at $95 \%$ level of confidence. We therefore rejected the null hypothesis (Ho:2), and upheld the alternate and restated, thus, there is a significance relationship between customers' performance management and customers' patronage in retail business sustainability in Port Harcourt, Rivers State, Nigeria.

Table 4: Correlation Matrix for data warehouse and retail business sustainability

\begin{tabular}{|c|c|c|c|c|}
\hline & & Data & Profitability & Customers' \\
\hline & & \multicolumn{2}{|l|}{ Warehouse } & Performance \\
\hline & Pearson Correlation & 1 & $.982^{* *}$ & $.972^{* *}$ \\
\hline \multicolumn{3}{|c|}{ Data Warehouse Sig. (2-tailed) } & .000 & .000 \\
\hline & $\mathrm{N}$ & 40 & 40 & 40 \\
\hline \multirow{3}{*}{ Profitability } & Pearson Correlation & $.982^{* *}$ & 1 & $.989^{* *}$ \\
\hline & Sig. (2-tailed) & .000 & & .000 \\
\hline & $\mathrm{N}$ & 40 & 40 & 40 \\
\hline \multirow{3}{*}{$\begin{array}{l}\text { Customers' } \\
\text { Patronage }\end{array}$} & Pearson Correlation & $.972^{* *}$ & $.989^{* *}$ & 1 \\
\hline & Sig. (2-tailed) & .000 & .000 & \\
\hline & $\mathrm{N}$ & 40 & 40 & 40 \\
\hline
\end{tabular}

**. Correlation is significant at the 0.01 level (2-tailed).

Source: Field Data 2020

The table 4 shows the correlation of hypotheses three and four; the hypothesis three show a significant correlation at $r=.982^{* *}$ where $\mathrm{P}$-value $=.000(\mathrm{P}<0.001)$. This implies a strong and significant relationship between both variables at $95 \%$ level of confidence. We therefore rejected the null hypothesis (Ho:3), and upheld the alternate and restated, thus, there is a significance relationship between data warehouse and retail business profitability in Port Harcourt, Rivers State, Nigeria. The hypothesis four show a significant correlation at $r=.972^{* *}$ where $\mathrm{P}$-value $=.000(\mathrm{P}<0.001)$. This implies a strong and significant relationship between both variables at $95 \%$ level of confidence. We therefore rejected the null hypothesis (Ho:4), and upheld the alternate and 


\section{Business Intelligence Applications; sustaining Retail Businesses in Rivers State, Nigeria}

restated, thus, there is a significance relationship between data warehouse and customers' patronage in retail business sustainability in Port Harcourt, Rivers State, Nigeria.

Table 5. Correlation Matrix for data mining and retail business sustainability

\begin{tabular}{lllll}
\hline \hline & & Data Mining & Profitability & $\begin{array}{l}\text { Customers' } \\
\text { Patronage }\end{array}$ \\
\hline \multirow{3}{*}{ Data Mining } & Pearson Correlation & 1 & $.977^{* *}$ & $.962^{* *}$ \\
& Sig. (2-tailed) & & .000 & .000 \\
& $\mathrm{~N}$ & 40 & 40 & 40 \\
Profitability & Pearson Correlation & $.977^{* *}$ & 1 & $.989^{* *}$ \\
& Sig. (2-tailed) & .000 & & .000 \\
& $\mathrm{~N}$ & 40 & 40 & 40 \\
Customers' & Pearson Correlation & $.962^{* *}$ & $.989^{* *}$ & 1 \\
Patronage & Sig. (2-tailed) & .000 & .000 & \\
& $\mathrm{~N}$ & 40 & 40 & 40 \\
\hline \hline
\end{tabular}

**. Correlation is significant at the 0.01 level (2-tailed).

Source: Field Data 2020

The table 5 shows the correlation of hypotheses five and six; the hypothesis five show a significant correlation at $r=.977^{* *}$ where $\mathrm{P}$-value $=.000(\mathrm{P}<0.001)$. This implies a strong and significant relationship between both variables at $95 \%$ level of confidence. We therefore reject the null hypothesis (Ho:5), and upheld the alternate and restated, thus, there is a significance relationship between data mining and retail business profitability in Port Harcourt, Rivers State, Nigeria. The hypothesis six show a significant correlation at $r=.962^{* *}$ where $P$-value $=.000(P<0.001)$. This implies a strong and significant relationship between both variables at $95 \%$ level of confidence. We therefore reject the null hypothesis (Ho:6), and upheld the alternate and restated, thus, there is a significance relationship between data mining and customers' patronage in retail business sustainability in Port Harcourt, Rivers State, Nigeria.

Table 6: Correlation Matrix for advanced data visualization and retail business Sustainability

\begin{tabular}{lllll}
\hline \hline & & $\begin{array}{l}\text { Advanced } \\
\text { Visualization }\end{array}$ & DataProfitability & \multicolumn{1}{c}{$\begin{array}{c}\text { Customers' } \\
\text { Patronage }\end{array}$} \\
\hline \multirow{2}{*}{ Advanced } & Pearson Correlation & 1 & $.978^{* *}$ & $.974^{* *}$ \\
Visualization & Sig. (2-tailed) & & .000 & .000 \\
& $\mathrm{~N}$ & 40 & 40 & 40 \\
& Pearson Correlation & $.978^{* *}$ & 1 & $.989^{* *}$ \\
Profitability & Sig. (2-tailed) & .000 & & .000 \\
& $\mathrm{~N}$ & 40 & 40 & 40 \\
& Pearson Correlation & $.974^{* *}$ & $.989^{* *}$ & 1 \\
Customers' & Sig. (2-tailed) & .000 & .000 & \\
Patronage & $\mathrm{N}$ & 40 & 40 & 40 \\
& & &
\end{tabular}

**. Correlation is significant at the 0.01 level (2-tailed).

Source: Field Data 2020

The table 6 shows the correlation of hypotheses seven and eight; the hypothesis six show a significant correlation at $r=.978^{* *}$ where $\mathrm{P}$-value $=.000(\mathrm{P}<0.001)$. This implies a strong and significant relationship between both variables at $95 \%$ level of confidence. We therefore reject the null hypothesis (Ho:7), and upheld the alternate and restated, thus, there is a significance relationship between advanced data visualization and retail business profitability in Port Harcourt, Rivers State, Nigeria. The hypothesis eight show a significant correlation at $r=.974^{* *}$ where $P$-value $=.000(P<0.001)$. This implies a strong and significant relationship between both variables at $95 \%$ level of confidence. We therefore reject the null hypothesis (Ho:8), and upheld the 


\section{Business Intelligence Applications; sustaining Retail Businesses in Rivers State, Nigeria}

alternate and restated, thus, there is a significance relationship between advanced data visualization and customers' patronage in retail business sustainability in Port Harcourt, Rivers State, Nigeria.

For the multivariate analysis, the partial correlation technique was used in testing the moderating effects of leadership style.

Table 7. Showing Partial Correlation of the moderating effect of organizational culture between business intelligence application and retail business sustainability

\begin{tabular}{|c|c|c|c|c|c|}
\hline \multicolumn{3}{|c|}{ Control Variables } & \multirow{3}{*}{$\begin{array}{l}\text { Business } \\
\text { Intelligence } \\
\text { Application } \\
1.000\end{array}$} & \multirow{2}{*}{\multicolumn{2}{|c|}{$\begin{array}{l}\text { Retail BusinessOrganizational } \\
\text { Sustainability culture }\end{array}$}} \\
\hline & & & & & \\
\hline \multirow{9}{*}{-none- ${ }^{a}$} & \multirow{3}{*}{$\begin{array}{l}\text { Business } \\
\text { Intelligence } \\
\text { Application }\end{array}$} & Correlation & & .992 & .997 \\
\hline & & Significance (2-tailed) & . & .000 & .000 \\
\hline & & Df & 0 & 38 & 38 \\
\hline & \multirow{3}{*}{$\begin{array}{l}\text { Retail Busine } \\
\text { Sustainability }\end{array}$} & Correlation & .992 & 1.000 & .992 \\
\hline & & Significance (2-tailed) & .000 & . & .000 \\
\hline & & Df & 38 & 0 & 38 \\
\hline & \multirow{3}{*}{$\begin{array}{l}\text { Organizational } \\
\text { culture }\end{array}$} & Correlation & .997 & .992 & 1.000 \\
\hline & & Significance (2-tailed) & .000 & .000 & . \\
\hline & & Df & 38 & 38 & 0 \\
\hline \multirow{6}{*}{$\begin{array}{l}\text { Organizati } \\
\text { onal } \\
\text { culture }\end{array}$} & Business & Correlation & 1.000 & .379 & \\
\hline & Intelligence & Significance (2-tailed) & . & .164 & \\
\hline & Application & Df & 0 & 37 & \\
\hline & & Correlation & .379 & 1.000 & \\
\hline & Retail Business & S Significance (2-tailed) & .000 & . & \\
\hline & & Df & 37 & 0 & \\
\hline
\end{tabular}

a. Cells contain zero-order (Pearson) correlations.

Source: Field Data 2020

In table 7 above, the zero-order partial correlation between Business Intelligence Application and Retail Business Sustainability shows the correlation coefficient where organizational culture is moderating the relationship; and this is, indeed, both very high $(0.997)$ and statistically significant ( $p$-value $(=0.000)<0.05)$. The partial correlation controlling for organizational culture however is $(0.379)$ and statistically significant $(p$-value $(=0.000)<0.05$.). The observed positive "relationship" between Business Intelligence Application and Retail Business Sustainability is due to underlying relationships between each of those variables and organizational culture. Looking at the zero correlation, we find that both Business Intelligence Application and Retail Business Sustainability are highly positively correlated with organizational culture, the control variable. Removing the effect of this control variable reduces the correlation between the other two variables to be 0.379 and it is significant at $\alpha=0.05$, therefore we rejected the null hypothesis and conclude that: Organizational culture significantly moderates the relationship between business intelligence application and retail business sustainability in Port Harcourt, Rivers State, Nigeria.

\section{DISCUSSION OF FINDINGS}

This study uses cross sectional survey design and descriptive statistic in investigating the demographic characteristics of the study respondents. While inferential statistical methods was used in the studied variables, while Pearson Product Moment Correlation Coefficient was used in testing the relationship between the predictor variable (business intelligence application) and the criterion variable (retail business sustainability) through the help of Statistical Package for Social Sciences (SPSS version 20.0) in retail business in Port Harcourt, Rivers State. The empirical findings revealed a positive and significant relationship between business intelligence application and retail business sustainability using Pearson Product Moment Correlation Coefficient at 95\% confidence interval, through Statistical Package for Social Science (SPSS) version 20.0. The empirical findings support the study of Mohammad, (2016), who concluded that, business intelligence application helps managers by breaking down information from various 


\section{Business Intelligence Applications; sustaining Retail Businesses in Rivers State, Nigeria}

resources in better basic leadership level both at tactical and strategic level, for customary utilization, conventional data frameworks farewell, yet for hierarchical and functional planning; new tools are required for business sustainability.

The first and second hypotheses shows that, there is a strong positive relationship between customers' performance management and measure of retail business sustainability profitability and customers' patronage of which the significant is based on $r=0.982 ; p=0.000<0.05$., and $r=0.995 ; p=0.000<0.05$., both at $95 \%$ confidence interval leading to the rejection of the null hypothesis $\left(\mathrm{H}_{0: 1}\right)$ and $\left(\mathrm{H}_{0: 2}\right)$, stated in the chapter one, and upheld the alternate and restated thus; there is a significant relationship between customers' performance management and profitability and customers' patronage. The third and fourth hypotheses shows that, there is a strong positive relationship between data warehouse and measure of retail business sustainability profitability and customers' patronage of which the significant is based on $r=0.992 ; p=0.000<0.05$, and $r=0.972 ; p=0.000<0.05$., both at $95 \%$ confidence interval leading to the rejection of the null hypothesis $\left(\mathrm{H}_{0: 3}\right)$ and $\left(\mathrm{H}_{0: 4}\right)$, stated in the chapter one, and upheld the alternate and restated thus; there is a significant relationship between data warehouse and profitability and customers' patronage.

The fifth and sixth hypotheses shows that, there is a strong positive relationship between data mining and measures of retail business sustainability profitability and customers' patronage of which the significant is based on $r=0.977 ; p=0.000<0.05$., and $r=0.962 ; p=0.000<0.05$., both at $95 \%$ confidence interval leading to the rejection of the null hypotheses $\left(\mathrm{H}_{0: 5}\right)$ and $\left(\mathrm{H}_{0: 6}\right)$, stated in the chapter one, and upheld the alternate and restated thus; there is a significant relationship between data mining and profitability and customers' patronage. The seventh and eighth hypotheses showed that, there is a strong positive relationship between advanced data visualization and measures of retail business sustainability profitability and customers' patronage of which the significant is based on $r=0.978 ; p=0.000<0.05$., and $r=0.974 ; p=0.000<0.05$., both at $95 \%$ confidence interval leading to the rejection of the null hypotheses $\left(\mathrm{H}_{0: 7}\right)$ and $\left(\mathrm{H}_{0: 8}\right)$, stated in the chapter one, and upheld the alternate and restated thus; there is a significant relationship between advanced data visualization and profitability and customers' patronage. This study finding support the empirical findings of Wolf, (2015), who concluded that, most visualization designs are to aid decision making and serve as tools that augment cognition. In designing and building a data visualization prototype, one must be guided by how the visualization will be applied. Data visualization is more than just representing numbers; it involves selecting and rethinking the numbers on which the visualization is based. According to David S., (2013) TDWI Research report third quarter on data visualization \& discovery for better business decision concluded that, the biggest trend in business intelligence and analytics today is selfservice. Users want tools and platforms that allow them to interact with data on their own without hands-on information technology (IT) development and supervision. Self-directed visual reporting and data discovery can free users throughout organizations to be more creative in their analysis and selection of visualizations to express insights.

The hypothesis nine shows that, there is a strong positive moderating effect between business intelligence application and retail business sustainability of which the significant is based on $r=0.997 ; p=0.000<0.05$., at $95 \%$ confidence interval. Looking at the zero-order correlation, we find that both Business Intelligence Application and Retail Business Sustainability are highly positively correlated with organizational culture, the control variable. Removing the effect of this control variable reduces the correlation between the other two variables to be 0.379 and it is significant at $\alpha=0.05$, therefore we reject the null hypothesis and conclude that: Organizational culture significantly moderates the relationship between business intelligence application and retail business sustainability in Port Harcourt, Rivers State, Nigeria.

\section{CONCLUSION}

In this study, the relationships between business intelligence application and retail business sustainability using customers' performance management, data warehouse, data mining and advanced data visualization and profitability and customers' patronage have been investigated. A survey seeking for the relationships has been conducted on a sample of 40 managerial staffs of selected retail outlets business in Port Harcourt, Rivers State, Nigeria. The study results showed significant positive relationship between the variables hypothesized in the research conceptual framework. Accordingly, the study strategy and methodology were designed in a way that points towards the achievement of the study objectives. The study concluded that business intelligence application through the use of customers' performance management, data warehouse, data mining and advanced data visualization significantly influences retail business profitability and customers' patronage. A scattered plot diagram was also plot to see the relationship between the predictor variable (business intelligence application) and the criterion variable (retail business sustainability). The scatter plot graph shows at $\mathrm{R}^{2}$ linear value of (0.963) depicting a strong viable and positive relationship between the two constructs. The implication is that an increase in business intelligence application simultaneously brings about an increase in the level of retail business sustainability. Customers' performance management has significant relationship on retail business sustainability - profitability and customers' patronage with a statistical correlation at $95 \%$ confidence. This indicates that, 


\section{Business Intelligence Applications; sustaining Retail Businesses in Rivers State, Nigeria}

customers' performance management is a great attribute of business intelligence application. Data warehouse in an organization found to have statistically significant correlation with profitability at $95 \%$ confidence, customers' patronage at $95 \%$ confidence. Data mining correlate significantly with profitability (at 95\% confidence), customers' patronage (at 95\% confidence). Advanced data visualization finding correlates significantly with profitability (at 95\% confidence), customers' patronage (95\% confidence). Organizational culture significantly moderates the relationship between business intelligence application and retail business sustainability (at $95 \%$ confidence). And removing the effect of this control variable reduces the correlation between the other two variables to be 0.379 and it is significant at $\alpha=0.05$.

\section{RECOMMENDATIONS}

Based on the conclusion of this study, the following recommendations are made:

Customers' performance management should be given proper priority as it enhances and detecting customer's performance level for effective service delivery.

i) Effective data warehouse is essential for successful decision making in business organization.

ii) Data analyst should be employed by management of retail business for proper functioning of data mining usage.

iii) Advance data visualization enhances effective reporting and data presentation for easy interpretation of business information.

iv) Retail business should adopt flexible organizational culture that accept change into their operations, as organizational culture system that resists change cannot benefits from the richness of business intelligence applications on business sustainability.

\section{REFERENCES}

1) Adesina A., (2018). Data is the new oil. www.https:/medium.com/@adeolaadesina. Retrieved on the 23 ${ }^{\text {rd }}$ of August, 2020.

2) Amit P. \& Kameshvari B., (2012). A study on consumer behaviour of organized and unorganized retail outlets in Vadodara City. International Journal of Engineering and Management Sciences, 3, (4), 466-474.

3) Al-Debei, M.M. (2011). Data warehouse as a backbone for business intelligence. European Journal of Economics, Finance, and Administrative Sciences, 33(4), 153-166.

4) Bertin, J., (2010). Semiology of graphics: Diagrams, networks, maps. Redlands, CA: Esri Press.

5) Borkin, M. A., Vo, A. A., Bylinskii, Z., Isola, P., Sunkavalli, S., Oliva, A., \& Pfister, H. (2013). What makes a visualization memorable? IEEE Transactions on Visualization and Computer Graphics, 19(12), 2306-2315. Available from: https://doi.org/10.1109/TVCG.2013.234. Accessed 29th March, 2020

6) Cândea, D. \& Oncică-Sanislav, D., (2008). Corporate sustainability: Concept and assessment. Review of management and economic engineering. 7(5), 129-132.

7) Dresner, H. (2015). Information technology and the growing use of location features in business intelligence software. Sand Hill.

8) Dhotre, M. (2010). Channel management and retail marketing. Himalaya Publishing House, Revised Edition.

9) Fernie S., Fernie J., \& Moore Ch., (2013). Principles of retailing. Edinburgh Business School, Heriot-Watt University

10) Few S. (2004). Dashboard Confusion. Accessed June 2020, from www.perceptualedge.com/articles/ie/dashboard_confusion.pdf

11) McKay, L., (2010). From organic goods to sustainable ones: A saturated market for organic packaged goods has sprouted a new demand: Sustainability," CRM Magazine, 14 (4), 14 - 19.

12) Olajide, O. (2018). Is the retail sector Nigeria's next big industry? Financial Nigeria Magazine.

13) Rasoul, D. G., \& Mohammad, H. (2016). A model of measuring the direct and impact of business intelligence on organizational agility with partial Mediatory role of Empowerment: Tehran construction engineering organization (TCEO) and EKTA organization industries.co. Social and Behavioural Sciences, 230(6), 413-421.

14) Reyan A., Ahmedl, T., \& Mohamed A., (2014). Generating data warehouse schema", International Journal in Foundations of Computer Science \& Technology, 4(2), 1-16

15) Rudrabasavaraj M. N., (2010). Dynamic global retailing management. Himalaya Publishing House, 1st Edition.

16) Sousa, M.J., (2020). Business intelligence for human capital management. International Journal of Business Intelligence Research, 11(1), $38-42$.

17) Sallam, R. (2017). Magic quadrant for business intelligence and analytics platforms. Accessed June 10, 2020. Available from: www.gartner.com/doc/3611117/magic-quadrant-business intelligence-analytics 


\section{Business Intelligence Applications; sustaining Retail Businesses in Rivers State, Nigeria}

18) Sharma B., (2008). Strategic retail management. Book Enclave.

19) Sancho, J. L. V., Dominguez, J. C. \& Ochoa, B. E. M., (2014). An approach to the taxonomy of data visualization. Journal Social Communication, 69(3), 486-507.

20) Torabi, A., Kiaian M. S., Dashti, V., Saeedi, M., \& Yousefi, N. (2018). A new prediction model based on cascade NN for wind power prediction. Computational Economics, 2(1), $45-50$.

21) Turban, E.; Sharda, R., \& Delen, D. (2010). Decision support and Business intelligence systems, 9th ed., Prentice Hall Press, Upper Saddle River NJ.

22) Tiwari R.S., (2009). Retail management, retail concepts and practices. Himalaya Publishing House, 1st edition.

23) Viégas, F. B. \& Wattenberg, M. (2007). Artistic data visualization: Beyond visual analytics.in proceedings of the 2nd international conference on online communities and social computing (pp.182- 191). Berlin, Heidelberg: Springer-Verlag. Available from http://dl.acm.org/citation.cfm?id=1784297.1784319.

24) Wixom, B. \& Watson, H. (2010). The business intelligence based organization. International journal of business intelligence research, 1(1), 12-24. 